\title{
Risk and clinical predictors of osteoporotic fracture in East Asian patients with chronic obstructive pulmonary disease: a population-based cohort study
}

Ping-Hsueh Lee ${ }^{1,2}$, Victor C Kok ${ }^{\text {Corresp., } 3,4,5}$, Po-Liang Chou ${ }^{6}$, Ming-Chang Ku ${ }^{2,7}$, Yu-Ching Chen ${ }^{4,5}$, JorngTzong Horng Corresp. 4, 5, 6

1 Department of Geriatric Medicine, Kuang Tien General Hospital, Taichung, Taiwan

3 KTGH Cancer Center, Kuang Tien General Hospital, Taichung, Taiwan

5 Disease Informatics Research Group, Asia University Taiwan, Taiwan

${ }^{6}$ Department of Computer Science and Information Engineering, National Central University, Jhongli, Taoyuan, Taiwan

7 Department of Diagnostic Radiology, Kuang Tien General Hospital, Taichung, Taiwan

Corresponding Authors: Victor C Kok, Jorng-Tzong Horng

Email address: victorkok@asia.edu.tw, horng@db.csie.ncu.edu.tw

Introduction: Osteoporosis is becoming an impending epidemic in the Asia-Pacific region. The association between risk of osteoporotic fracture (OTPF) and chronic obstructive pulmonary disease (COPD) in East Asian patients is yet to be fully examined. We conducted a nationwide population-based retrospective cohort study of 98,700 patients aged $\geq 50$ years with or without COPD using a national administrative claims dataset.

Materials and Methods: The patients were divided into COPD and comparison groups comprising 19,740 and 78,960 patients, respectively. The groups were 1 to 4 matched for age, gender, index date, diabetes mellitus, pre-existing osteoporosis and chronic kidney disease. Information such as the geographic area where southern part represented more sunshine exposure, smoking-related diagnoses, alcohol use disorder, whether there was regular use of inhaled corticosteroids and oral corticosteroids, vitamin D prescriptions, Charlson-Deyo comorbidity index score, and other relevant medical comorbidities were extracted for analysis. They were followed up until OTPF or the end of the year 2013. The outcome measure was an osteoporotic vertebral fracture and other long-bone fractures. A multivariate Cox model was constructed to derive adjusted hazard ratios (aHR) for OTPF with corresponding 95\% confidence intervals $(\mathrm{Cl})$ after controlling for age, sex, insurance premium category, vitamin D prescription, osteoporosis, and coronary heart disease (CHD). Kaplan-Meier curves of the probability of OTPF-free survival for each cohort were compared using the log-rank test. Patients with OTPF during the first follow-up year were excluded from the overall risk calculation. Contributing factors to the increased risk of OTPF in COPD patients were examined in a sensitivity analysis.

Results: After a total follow-up of 68,743 patient-years for the COPD group and 278,051 patient-years for the matched comparison group, the HR for OTPF was $1.24(95 \% \mathrm{Cl}, 1.02-1.51 ; \mathrm{P}=0.0322)$ in COPD patients. The aHR was increased by $30 \%$ for vertebral OTPF $(a H R=1.297,95 \% \mathrm{Cl} 1.020-1.649 ; \mathrm{P}=$ 0.0339). Differential lag time sensitivity analysis revealed a progressively elevated risk up to 8-fold increase in women $(\mathrm{aHR}=8.0(95 \% \mathrm{Cl}, 1.81-35.4 ; \mathrm{P}<0.01)$ during the fifth follow-up year. COPD patients with pre-existing osteoporosis or given vitamin D prescription harbor a sustained increased risk up to the 5th (aHR, 4.1; 95\% Cl, 1.61-10.35) and third (aHR, 2.97; 95\% Cl, 1.48-5.97) follow-up year, 
respectively.

Conclusions: Our nationwide population-based cohort study demonstrates that East Asian COPD patients aged 50 and beyond do harbor a modestly increased risk for osteoporotic vertebral fractures particularly who are female, have pre-existing osteoporosis or require vitamin $\mathrm{D}$ prescription. 


\section{Risk and clinical predictors of osteoporotic fracture in East Asian}

2 patients with chronic obstructive pulmonary disease: a population-

3 based cohort study

4

5 Short Title: Osteoporotic fracture in Asians with COPD

6

7 Ping-Hsueh Lee ${ }^{1,2}$, MD; Victor C. Kok ${ }^{3,4,5, ~ *, ~ M D, ~ P h D, ~ F A C P ; ~ P o-L i a n g ~ C h o u ~}{ }^{6}$, BSc; Ming-

8 Chang $\mathrm{Ku}^{2,7}$, MD; Yu-Ching Chen ${ }^{3,5}$, PhD; Jorng-Tzong Horng ${ }^{3,}$, 6, * , PhD.

${ }^{1}$ Department of Geriatric Medicine, Kuang Tien General Hospital, Taichung, Taiwan

${ }^{2}$ Jen-Te Junior College of Medicine, Nursing and Management, Miaoli County, Taiwan

${ }^{3}$ Disease Informatics Research Group, Asia University Taiwan, Taichung, Taiwan ${ }^{4}$ Department of Internal Medicine, Kuang Tien General Hospital, Taichung, Taiwan

${ }^{5}$ Department of Bioinformatics and Medical Engineering, Asia University Taiwan, Taichung, 15 Taiwan

${ }^{6}$ Department of Computer Science and Information Engineering, National Central University,

17 Jhongli, Taiwan

${ }^{7}$ Department of Radiology, Kuang Tien General Hospital, Taichung, Taiwan.

$20 *$ Corresponding authors:

21 Victor C. Kok, MMedSc, MD, PhD, FACP

22 Kuang Tien General Hospital

23117 Shatien Road Shalu, Taichung 43303, Taiwan

24 Tel: +8864 26625111, ext: 2263

25 Fax: +886426655050

26 E-mail: victorkok@asia.edu.tw

27

28 Jorng-Tzong Horng, $\mathrm{PhD}$

29 Department of Computer Science and Information Engineering

30 National Central University 
31300 Jhongda Road, Jhongli, Taoyuan 32001, Taiwan

32 Tel +886919057555

33 E-mail: horng@db.csie.ncu.edu.tw

34

35 Tables: 4 (including one supplement table)

36 Figures: 4 (including one supplement figure)

37 Word count of the main manuscript: 3717

38 Abstract word count: 413 
39 Abstract

40

41 Introduction: Osteoporosis is becoming an impending epidemic in the Asia-Pacific region. The

42 association between risk of osteoporotic fracture (OTPF) and chronic obstructive pulmonary

43 disease (COPD) in East Asian patients is yet to be fully examined.

44 We conducted a nationwide population-based retrospective cohort study of 98,700 patients aged

$45 \geq 50$ years with or without COPD using a national administrative claims dataset.

46 Materials and Methods: The patients were divided into COPD and comparison groups

47 comprising 19,740 and 78,960 patients, respectively. The groups were 1 to 4 matched for age,

48 gender, index date, diabetes mellitus, pre-existing osteoporosis and chronic kidney disease.

49 Information such as the geographic area where southern part represented more sunshine

50 exposure, smoking-related diagnoses, alcohol use disorder, whether there was regular use of

51 inhaled corticosteroids and oral corticosteroids, vitamin D prescriptions, Charlson-Deyo

52 comorbidity index score, and other relevant medical comorbidities were extracted for analysis.

53 They were followed up until OTPF or the end of the year 2013. The outcome measure was an

54 osteoporotic vertebral fracture and other long-bone fractures. A multivariate Cox model was

55 constructed to derive adjusted hazard ratios (aHR) for OTPF with corresponding 95\% confidence

56 intervals (CI) after controlling for age, sex, insurance premium category, vitamin D prescription,

57 osteoporosis, and coronary heart disease (CHD). Kaplan-Meier curves of the probability of

58 OTPF-free survival for each cohort were compared using the log-rank test. Patients with OTPF

59 during the first follow-up year were excluded from the overall risk calculation. Contributing

60 factors to the increased risk of OTPF in COPD patients were examined in a sensitivity analysis.

61 Results: After a total follow-up of 68,743 patient-years for the COPD group and 278,051

62 patient-years for the matched comparison group, the HR for OTPF was 1.24 (95\% CI, 1.02-1.51;

$63 \mathrm{P}=0.0322)$ in COPD patients. The aHR was increased by $30 \%$ for vertebral OTPF $(\mathrm{aHR}=$

64 1.297, 95\% CI 1.020-1.649; P = 0.0339). Differential lag time sensitivity analysis revealed a

65 progressively elevated risk up to 8-fold increase in women $(\mathrm{aHR}=8.0(95 \% \mathrm{CI}, 1.81-35.4 ; \mathrm{P}<$

66 0.01) during the fifth follow-up year. COPD patients with pre-existing osteoporosis or given

67 vitamin D prescription harbor a sustained increased risk up to the $5^{\text {th }}(\mathrm{aHR}, 4.1 ; 95 \% \mathrm{CI}, 1.61-$

68 10.35) and third (aHR, 2.97; 95\% CI, 1.48-5.97) follow-up year, respectively. 
69 Conclusions: Our nationwide population-based cohort study demonstrates that East Asian

70 COPD patients aged 50 and beyond do harbor a modestly increased risk for osteoporotic

71 vertebral fractures particularly who are female, have pre-existing osteoporosis or require vitamin

72 D prescription.

73 (Word count: 413)

74 .

75 Keywords: COPD, osteoporotic fracture, Asian, longitudinal study, osteoporosis 


\section{Introduction}

78 Osteoporosis is the most common bone disease in the world and is characterized by low 79 bone mass and derangement of bone microarchitecture. The prevalence of osteoporotic fracture

80 (OTPF) was estimated to be 9.0 million worldwide in the year 2000 (Johnell \& Kanis 2006). In a 81 cohort of Chinese women, the prevalence rates of primary osteoporosis affecting the spine, 82 femoral neck, and hip were reported to be 32\%-34\%, 16.3\%, and 18.9\%, respectively (Wu et al. 83 2004). In other Asian countries, the prevalence rate of osteoporosis in women $\geq 50$ years has been 84 reported as 34\% in Korea and 31\% in Japan (Choi et al. 2012; Iki et al. 2001). OTPF results in 85 significant reductions in quality of life due to pain, depression, and disability (Poole \& Compston 2006). Elderly patients who sustain nondisplaced hip fractures experience predictable and lasting loss of function, particularly in patients with pulmonary disease. Both age and chronic obstructive pulmonary disease (COPD) affect the speed of functional recovery (Eisler et al. 2002). Furthermore, the mortality rate following hip fracture reportedly was as high as $36 \%$ in a systemic epidemiological review (Abrahamsen et al. 2009). The estimated cost of treatment of osteoporosis-related fracture in the United States was approximately \$17 billion in 2005 and is estimated to increase to $\$ 25.3$ billion by 2025 (Burge et al. 2007).

Despite the substantial clinical burden of osteoporosis, treatment rates are low in some East Asian countries. In a national screening program in Korea, the estimated treatment rate was only $14.4 \%$ in osteoporotic women (Choi et al. 2012). Because low bone mineral density (BMD) is a major risk factor for fractures, timely treatment can prevent this disastrous outcome (Nelson et al. 2010). Therefore, early identification of high-risk patients is an important step toward sufficient to detect high-risk patients in a timely and cost-effective manner (Ogura-Tomomatsu et al. 2012; Schuit et al. 2004).

Patients with COPD have many shared features with osteoporotic patients, such as low body mass index (BMI), inactivity, and chronic steroid use. COPD has been shown to be associated with low BMD in recent studies (Jaramillo et al. 2015; Looker 2014). However, the association between risk of OTPF and COPD has not been well studied, particularly in the Asian population. The prevalence of osteoporosis has been shown to be higher in COPD patients compared with controls (Graat-Verboom et al. 2009; Schnell et al. 2012), and the prevalence of hip fracture was reportedly higher in a cross-sectional study of 465 COPD patients in Brazil (Kulak et al. 2010). 
108 To date, no studies have been reported from East Asian countries regarding the magnitude of the 109 risk of subsequent OTPF contributed by each clinical predictor in COPD patients. The aim of the 110 present study was to evaluate the association between COPD and risk of OTPF and identify

111 clinical predictors of fracture in East Asian patients. The magnitude of the risk of OTPF

112 contributed by clinical predictors would be calculated.

113

114 Materials and Methods

115 Data source

116 Data from 2007 to 2013 was obtained from the Longitudinal Health Insurance Dataset 117 (LHID) of the National Health Insurance Research Database (NHIRD). The National Health 118 Insurance (NHI) program, established in 1995 in Taiwan, is a mandatory health insurance 119 program requiring every resident, from a newborn to an elderly person, to join. It provides 120 comprehensive insurance coverage for medical services through outpatients, inpatients, and 121 emergency departments, in addition to traditional Chinese medicine. The program currently has a 122 coverage rate of 99\%. LHID consists of 1 million beneficiaries randomly sampled from NHIRD.

123 The dataset includes NHI enrolment files and claims data, such as examinations, medical 124 procedures, drug prescriptions, and diagnoses, of all included patients. The International 125 Classification of Diseases, Ninth Revision, Clinical Modification codes (ICD-9-CM codes; 2001 126 revision) were used by physicians to code diseases in the system. All recognizable personal 127 information was encrypted according to regulations specified by the Bureau of NHI. The authors 128 have successfully conducted several population-based retrospective cohort studies using the 129 LHID (Kok et al. 2014; Kok et al. 2016; Kok et al. 2015a; Kok et al. 2015b). The present study 130 was approved by the accredited local in-house Institutional Review Board with a certificate 131 number KTGH-IRB 10520. The IRB approved that no any form of consent (Verbal / Written) 132 was required for this study.

134 Study Design

135 We conducted a population-based, observational, cohort study to assess the association 136 between COPD and risk of OTPF. All patients diagnosed with COPD between January 2007 and 137 December 2013 were identified (ICD-9 CM: 490-492, 496). The index date was defined as the 138 month in which the diagnosis of COPD was made. Exclusion criteria were as follows: (1) age 
$139<50$ years; (2) less than two COPD outpatient claims within 1 year with no inpatient records; and

140 (3) pre-existing COPD or OTPF before January 1, 2007. The control group was composed of the

141 remaining patients in LHID without COPD, with 1 to 4 matched for age, gender, and index

142 month, diabetes mellitus, pre-existing osteoporosis and chronic kidney disease. The exclusion

143 criteria applied to the COPD group was used for the control group. All study patients were

144 followed up until the first incidence of OTPF which was further separated into vertebral fractures

145 and the other long bone fractures, drop-out from the insurance program, or the end of the present 146 study.

147

148 Data extraction

149 Patients age, gender, date of accrual, geographic residential area, insurance premium 150 category, behavioral proxies such as smoking related diagnoses and alcohol use disorders;

151 medical comorbidities including diabetes mellitus, pre-existing osteoporosis, chronic kidney

152 disease, rheumatoid arthritis, hypertension, dyslipidemia, coronary heart disease, chronic liver

153 disease, stroke and dementia; medical prescriptions such as vitamin $\mathrm{D}$, inhaled corticosteroids

154 (ICS: budesonide, beclomethasone, ciclesonide, fluticasone) and oral corticosteroids (OCS:

155 cortisone acetate, dexamethasone, fludrocortisone, methylprednisolone, prednisolone,

156 triamcinolone); and Charlson-Deyo Comorbidity Index Score were collected from the dataset

157 and calculated. Longitudinal tracking data of study participants until the occurrence of a specific

158 type of osteoporotic fracture, e.g., vertebral fracture or femoral neck fracture were extracted.

159 Candidates who would be included were also screened for pathological fractures due to cancer

160 metastases (ICD-9-CM code 198.5), renal osteodystrophy (588.0) and secondary

161 hyperthyroidism (588.81).

162

163 Outcome measures

164 The primary outcome measure of the present study was OTPF, defined as any pathological 165 fracture due to osteoporosis (ICD-9-CM codes: 733.0x + 733.1x) documented in inpatient or 166 outpatient data files during the study period. Osteoporotic vertebral fracture has a unique code as 167 733.13. To prevent overstated or false claiming, NHI randomly and regularly reviews claims 168 data, including patient history and laboratory and imaging reports. Only cases with correct 169 coding for all diagnoses are eligible for full reimbursement. Any violation of the coding 
170 regulations results in payment retrieval plus a punitive fine, which may be several times the

171 original payment. To ensure accuracy, all coding procedures were performed by groups of

172 specialists assigned by contributing hospitals. OTPF in the present study was defined as any new

173 and matched ICD-9 coding of cohort subjects between 2007 and 2013 in outpatient, emergent, or

174 inpatient settings. Therefore, we believe that all events that occurred during the follow-up period

175 were recorded with a high degree of accuracy. Furthermore, we excluded pathological fractures

176 that resulted from cancer metastasis, renal osteodystrophy, or secondary hyperparathyroidism

177 [ICD-9-CM codes: 733.1 + (198.5,588.0, or 588.1)] (Supplement Table 1). Patients with OTPF

178 during the first follow-up year were excluded from the overall risk calculation.

179

180 Covariates and confounders

181 Socioeconomic status of participating subjects was approximated using different category

182 by insurance premium. Exposure to different levels of sunshine was also taken into account by

183 the use of the residential area of the participating subjects (more sunshine in the southern part of

184 the country). Lifestyle factors included smoking-related diagnoses and alcohol used disorder

185 were used as proxies for cigarette smoking and alcohol drinking were extracted. Medication

186 history of inhaled corticosteroid and/or oral corticosteroid use and vitamin D prescription were

187 extracted from the dataset. Comorbidities were identified according to ICD-9-CM codes,

188 including rheumatoid arthritis, hypertension, dyslipidemia, coronary heart disease (CHD), liver

189 disease, stroke, and dementia. An overall score of the Charlson-Deyo comorbidity index of each

190 patient was collected.

191

192 Statistical analysis

193 Patient-year data and incidence rates were evaluated. A multivariate Cox model was

194 constructed to derive adjusted hazard ratios (aHR) with corresponding 95\% confidence intervals

195 (CI) after controlling for factors that were revealed significant in the univariate Cox model so

196 that overadjustment (overfitting) and noise could be avoided. Fracture-free survival was assessed

197 using the Kaplan-Meier analysis. Survival curves were compared between COPD and non-

198 COPD groups using the log-rank test. Differential lag time sensitivity analysis was carried out to

199 examine the effect of different exposure time lag on the risk of osteoporotic fractures among

200 COPD patients who possessed the characteristic such as female and specific medical 
201 comorbidity. We used the bivariate Cox model to evaluate the risk of OTPF in COPD when

202 coupled with each medical comorbidity. P-values of $<0.05$ were considered statistically

203 significant. All study analyses were performed using the SPSS statistical software (IBM SPSS

204 Statistics Version 22).

205

206 Results

207 Characteristics of the study population

208 From 2007 to 2013, 92,656 newly-diagnosed COPD patients were identified from LHID (n $209=965,659)$. Among these, 70,191 were excluded after applying the exclusion criteria described 210 above. Reasons for exclusion were as follows: incomplete data registration $(\mathrm{n}=1,310)$ and 211 unsuccessful matching $(n=5,635)$. As a result, 19,740 patients were recruited to the COPD sub212 cohort and 78,960 to the non-COPD sub-cohort after 1 to 4 matching for age, gender, index 213 month, diabetes mellitus, pre-existing osteoporosis and chronic kidney disease. The mean age 214 (and standard deviation) in the COPD group was 66 years (10.23), with $62.5 \%$ of patients $<70$ 215 years of age. COPD patients were predominantly male (55.8\%). The mean follow-up duration 216 was 2.97 years (standard deviation (SD), 2.06 years) in the COPD group and 3.01 years (SD, 2172.05 years $)$ in the non-COPD group, which were not statistically significantly different $(\mathrm{P}=$ 218 0.0949). Hypertension and hyperlipidemia were the most commonly observed co-morbidities. 219 Except for dyslipidemia, all non-matching co-morbidities, such as rheumatoid arthritis, 220 hypertension, and coronary heart disease, were differently distributed between the two groups.

221 The mean Charlson Comorbidity Index (CCI) score was significantly higher in the COPD sub222 cohort (1.14 vs. 1.02; $\mathrm{P}<0.0001$; Table 1). More patients with COPD were classified as a 223 regular user of oral prednisolone $(16.9 \%$ vs. $6.4 \%$; $\mathrm{P}<0.001$; Table 1$)$.

224

225 Incidence of OTPF

226 There were 131 OTPF events in the COPD group during the study period (68,743 patient227 years), with an incidence rate of 1.91/1,000 patient-years. In the comparator group matched for 228 age, gender, index month, diabetes mellitus, chronic kidney disease and pre-existing 229 osteoporosis, there were 429 OTPF events in 278,051 patient-years, with an incidence rate of $2301.54 / 1,000$ patient-years. Patients with COPD were significantly more likely to have OTPF 231 [crude hazard ratio (HR), 1.24; 95\% CI, 1.02-1.51; P =0.0322; Table 2], as demonstrated by 
232 separation of the two cumulative incidence curves (Figure 2) and osteoporotic fracture-free 233 survival curves in the Kaplan-Meier analysis (Supplement Figure 1).

234 After multivariate Cox proportional hazards regression controlling for sex, age, vitamin D 235 prescription, insurance premium category, pre-existing osteoporosis and coronary heart disease, 236 the difference between the two groups lost statistical significance (aHR, 1.21; 95\% CI, 0.992 237 1.469; $\mathrm{P}=0.0597)$. However, when the outcome was a vertebral OTPF, both crude HR (1.33; 238 $95 \% \mathrm{CI}, 1.05-1.69 ; \mathrm{P}=0.0189)$ and aHR $(1.297 ; 95 \% \mathrm{CI}, 1.020-1.649 ; \mathrm{P}=0.00339)$ were statistically significant. Figure 3 demonstrates the clear separation of the two cumulative incidence curves. Owing to few events as long bone fracture, the crude HRs were nonsignificantly increased, for example, in ulnar fractures and femoral neck fracture (Table 2).

It is noteworthy that COPD patients who were older (up to 7.5-fold increase of the risk in 243 terms of aHR in patients aged $>80$ years as compared with the age group of 50-59 years), female 244 (3.8-fold increase), who received vitamin D prescriptions (3.3-fold increase), with pre-existing osteoporosis (3-fold increase) or with coronary heart disease (1.5-fold increase) had higher risk for OTPF than their non-COPD comparators (Table 2). In sensitivity analysis based on differential lag time with vertebral OTPF as the outcome, female COPD patients had a sustained and progressively increased risk of vertebral OTPF compared with non-COPD females from the second $(\mathrm{aHR}=3.3 ; 95 \% \mathrm{CI}, 1.89-5.74 ; \mathrm{P}<0.0001)$ to fifth $(\mathrm{aHR}=8.0 ; 95 \% \mathrm{CI}, 1.81-35.4 ; \mathrm{P}<$ 0.01 ) follow-up year. In COPD patients with pre-existing osteoporosis, the risk of vertebral OTPF, approximately 3 to 4 -fold increased, sustained through to the fifth follow-up year. COPD patients who were co-prescribed vitamin $\mathrm{D}$ had an statistically significantly increased risk in the 253 second $(\mathrm{aHR}=3.62 ; 95 \% \mathrm{CI}, 2.1-6.23 ; \mathrm{P}<0.0001)$ and third $(\mathrm{aHR}=2.97 ; 95 \% \mathrm{CI}, 1.48-5.97$; $\mathrm{P}<0.01$ ) follow-up year (Table 3). Comorbidities, such as rheumatoid arthritis, diabetes

255

256

257 258 259 260 261 262

mellitus, hypertension, dyslipidemia, CKD, liver disease, stroke, or dementia, were not associated with OTPF. In addition, steroid exposure, smoking related diagnoses, alcohol use disorders, and geographic region, were not associated with OTPF (Table 2).

\section{Discussion}

We believe this to be the first longitudinal cohort study with a meticulous study design to examine the relationship between COPD and risk of OTPF, particularly vertebral fracture, in an East Asian population. Compared with the comparison cohort matched for age, gender, index 
263 month, pre-existing osteoporosis, diabetes mellitus and chronic kidney disease, Asian COPD 264 patients had a significantly increased risk of developing OTPF, with a crude HR of 1.24 (95\% 265 CI, 1.02-1.51). When we examine the OTPF by site, the risk for vertebral fractures in COPD 266 patients increases by approximately 30\% even after statistical adjustment for confounding 267 factors. In addition to pre-existing osteoporosis, female gender and those who require vitamin D 268 prescription were important clinical predictors of vertebral OTPF in the COPD population.

269 Chen and colleagues published a retrospective cohort study to examine the risk for 270 osteoporosis in COPD patients in the same region as ours (Chen et al. 2015) Nevertheless, the 271 study reveals some shortcomings: first, pathological fractures resulted from bone metastases, 272 renal osteodystrophy and hyperparathyroidism were not excluded; second, comparators were not 273 matched for pre-existing osteoporosis, diabetes mellitus, and chronic kidney disease; third, 274 vitamin D prescription was not taken into account; and lastly, a half of the COPD cohort aged 275 below 50 years, which are not an optimal population to examine osteoporosis for. Another 276 population-based retrospective cohort study to examine the association between COPD and hip 277 fracture (Huang et al. 2016) revealed that patients with COPD had an approximately 60\% greater 278 risk of sustaining hip fracture. Our study cannot confirm this association (crude HR = 2.319; $27995 \% \mathrm{CI}, 0.68-7.92 ; \mathrm{P}=0.1797)$. Further studies are needed to confirm the potentially existing 280 risk.

281 The prevalence of osteoporosis was significantly higher in COPD patients compared with 282 healthy subjects, with prevalence rates of 9\%-69\% in COPD patients (Graat-Verboom et al. 283 2009). The association between COPD and osteoporosis has been reported in many studies. In a 284 very elderly Chinese male population, COPD was found to be independently associated with low 285 femoral neck bone mineral density (Bian et al. 2015). Higher Global Initiative for Chronic 286 Obstructive Lung Disease (GOLD) stage is reportedly correlated with lower bone mineral 287 density, with every unit decrease in respiratory function (expressed as FEV1 in L/s) associated 288 with a decrease in BMD of approximately $0.02 \mathrm{~g} / \mathrm{cm}^{2}$ (Lekamwasam et al. 2002; Lekamwasam 289 et al. 2005; Vrieze et al. 2007). This association was independent of potential confounding 290 factors, such as age, smoking habit, major comorbidity, and medications.

291 However, only a few studies have examined whether patients with COPD have a higher risk 292 of developing OTPF. A recent small cross-sectional study reported by Watanabe and colleagues 293 reveals that the prevalent vertebral fracture is as high as $79.4 \%$ in Japanese men with COPD 
294 (Watanabe et al. 2015). A case-control study demonstrated an independent association between 295 COPD and increased risk of hip fracture in Catalonians (Reyes et al. 2014). In a multicenter 296 cross-sectional study, Diez-Manglano and colleagues observed a high probability of fracture in 297347 Spanish COPD inpatients. Overall, nearly half of the COPD patients (95\% CI, 44.8-54.7) 298 had a probability of hip fracture in the next 10 years. The probability of fracture was not related 299 to the GOLD stage. An American retrospective observational study of 87,360 COPD veterans 300 reported a high incidence rate of hip fractures during 4 years of follow-up, with 3.99 events/1000 301 person-years (Morden et al. 2011). However, this study did not include a comparative cohort for 302 the study population. None of the studies mentioned above used a prospective design method. In 303 a further study with a 6-year follow-up of 5,541 males in the general population, patients with 304 COPD or asthma had lower BMD than patients without COPD or asthma, with adjusted odds 305 ratio for vertebral and non-vertebral fractures of 2.6 and 1.4, respectively (odds ratio for presence 306 of COPD or asthma vs. absence of COPD or asthma, 2.64; 95\% CI, 1.57-4.44; and 1.42; 95\% 307 CI, 1.03-1.96, respectively) (Dam et al. 2010). However, the inclusion of patients with asthma 308 limited the ability to evaluate the contribution of COPD to fracture outcomes. Because the 309 abovementioned studies were conducted in the western population and three included men only 310 (Dam et al. 2010; Morden et al. 2011; Reyes et al. 2014), the generalizability to populations in 311 Eastern countries is questionable.

312 The association between COPD and OTPF observed in the present study may be 313 attributable to shared risks between both conditions, such as smoking, physical inactivity, low 314 body weight, and malnutrition (Biskobing 2002; Dam et al. 2010; Jorgensen \& Schwarz 2008). 315 Moreover, serum vitamin D levels may also contribute to the risk of OTPF. It has been shown 316 that decreased vitamin D levels were independently associated with increased risk of 317 osteoporosis (defined as vertebral fracture without decreased BMD) by 7.5-fold (Graat-Verboom 318 et al. 2012).

319 It should be noted that OTPF may result from events other than osteoporosis, such as falls. 320 COPD patients typically have many shared risk factors for falls, such as muscle weakness, 321 mobility impairment, and exercise intolerance (Kim et al. 2008; Ries et al. 2007). Compared with 322 healthy controls, the presence of COPD has been shown to be associated with significantly 323 impaired ability to perform balance tests, such as the Berg Balance Scale, timed up and go test, 324 and single-leg stance (Crisan et al. 2015; Porto et al. 2015). An observational cohort study 
325 reported a high prevalence of previous falls in COPD patients (32\%), with an incidence rate of

3260.1 (95\% CI, 0.06-0.14) falls/person-month (Roig et al. 2011). In a population-based study,

327 Sibley et al. reported that COPD was significantly associated with increased risk of falls (Sibley

328 et al. 2014). Thus, in addition to osteoporosis, risk factors for falls may play an important role in

329 the correlation between COPD and OTPF. The treatment of such risk factors and osteoporosis is

330 likely required for successful fracture prevention.

331 Patients with CKD are at an increased risk of fragility fracture (Nickolas et al. 2008), which

332 may be explained by CKD-related bone mineral disease and high coprevalence of CKD and

333 osteoporosis in elderly individuals (Klawansky et al. 2003). This is the reason why our study

334 design employed matching the comparison group by this factor.

335 The present study had some clinical implications. According to current guidelines,

336 osteoporosis screening is not recommended for patients with COPD. In the present study, we

337 identified COPD as a potential risk factor for OTPF, particularly vertebral OTPF and the

338 contributing predictors of vertebral OTPF are female COPD patients or those with pre-existing

339 osteoporosis or required vitamin D prescription. Timely arrangement of BMD scanning may

340 increase the possibility of treating osteoporosis and reduce the risk of fracture in this high-risk

341 population. Systemic corticosteroid should be used with cautious as the incidence of fracture

342 increases with duration and dosage of steroid therapy (Canalis et al. 2007; Reid \& Heap 1990).

343 Because $87 \%-90 \%$ of elderly fractures result from falls (Dargent-Molina et al. 1996; Fife \&

344 Barancik 1985), strategies to prevent falls should be implemented in at-risk patients, such as

345 medication review, environmental adjustment, and exercise training. Previous studies have

346 shown that balance training in COPD patients has utility in improving important fall-related

347 factors, such as function, muscle strength, and balance performance (Beauchamp et al. 2013;

348 Harrison et al. 2015). Thus, introducing balance training component into currently existing

349 exercise programs for COPD patients may be of more value in OTPF prevention.

350 Several limitations of the present study have to be acknowledged. First, we were unable to

351 obtain data regarding important fracture risk factors, including BMI, bone marrow density, and

352 calcium intake, family history of OTPF, and physical activity level. Second, the propensity for

353 falls could not be determined because data for risk factors, such as gait abnormality, visual

354 impairment, and living environment, were unavailable. Third, COPD diagnoses were obtained

355 from a claimed dataset, which might not be as accurate as diagnoses made by standardized 
356 protocols or tools. However, we excluded outpatients claiming less than two times per year 357 without an inpatient record to increase accuracy. Lastly, the true incidence of prevalent fracture 358 which is existent morphological fracture identified by $\mathrm{x}$-ray during the study period cannot be 359 determined. In the current study, the authors only picked up "clinical fractures" with symptoms 360 because most patients were not taking screening spinal x-ray exams. Thus, upon subject 361 recruitment, a prevalent asymptomatic vertebral fracture can potentially be missed. Similarly, the

362 fracture that this research was looking at was physician-diagnosed clinical fracture identifiable in

363 the national claims database. Thus, the true vertebral fracture incidence during the study period is 364 unknown. Thanks to the nationwide frailty intervention health programs established in Taiwan 365 aiming to reduce the risk of falls and fractures, many if not all asymptomatic pre-clinical 366 vertebral OTPFs have already been screen-detected. The risk of misclassification bias is thus 367 much reduced.

368 The study has several strengths. First, we used compulsory administrative data to identify 369 our study cohorts, which avoids possible volunteer or selection bias. Second, patients in the 370 COPD group of the present study were meticulously matched with individuals without COPD, 371 thereby minimizing possible confounding or bias that may affect other observational studies.

372 Third, the sample of the present study was large and nationwide, increasing the generalizability 373 of the present findings. We believe the effect of the large sample size of the present study may 374 overcome some of the confounding factors caused by minor issues, such as code

375 misclassification and minor differences between the two cohorts or use of medications that effect 376 bone metabolism. Fourth, we excluded patients with fractures that occurred within the first year 377 of COPD diagnosis, which may have been caused by other factors as the time was too short for 378 COPD to have affected bone metabolism.

379 In conclusion, the present large-scale longitudinal study conducted in the Asia-pacific 380 region found an association between OTPF in COPD patients. Among patients with COPD, the 381 risk of fractures was significantly increased in female patients, and those with a diagnosis of 382 osteoporosis, or those who require vitamin D prescription indicating risk for osteoporosis. These 383 results indicate the importance of fall prevention and osteoporosis treatment in patients with 384 COPD. Further prospective cohort studies are required to confirm the causal relationship 385 between COPD and OTPF. 


\section{Acknowledgements}

389 The authors wish to thank the Administration of the National Health Insurance and the National 390 Health Research Institute, Taiwan, for the dataset used to conduct this research. The 391 interpretation and conclusions contained herein do not represent those of the institutions above. 392 
393

394

395

396

397

398

399

400

401

402

403

404

405

406

407

408

409

410

411

412

413

414

415

416

417

418

419

420

421

422

423

424

425

426

427

428

429

430

431

432

433

434

435

\section{References}

Abrahamsen B, van Staa T, Ariely R, Olson M, and Cooper C. 2009. Excess mortality following hip fracture: a systematic epidemiological review. Osteoporos Int 20:1633-1650. 10.1007/s00198-009-0920-3

Beauchamp MK, Janaudis-Ferreira T, Parreira V, Romano JM, Woon L, Goldstein RS, and Brooks D. 2013. A randomized controlled trial of balance training during pulmonary rehabilitation for individuals with COPD. Chest 144:1803-1810. 10.1378/chest.13-1093

Bian P, Li X, Ying Q, Chen J, Jin X, Yao J, and Shou Z. 2015. Factors associated with low femoral neck bone mineral density in very elderly Chinese males. Arch Gerontol Geriatr 61:484488. 10.1016/j.archger.2015.08.010

Biskobing DM. 2002. COPD and osteoporosis. Chest 121:609-620.

Burge R, Dawson-Hughes B, Solomon DH, Wong JB, King A, and Tosteson A. 2007. Incidence and economic burden of osteoporosis-related fractures in the United States, 2005-2025. J Bone Miner Res 22:465-475. 10.1359/jbmr.061113

Canalis E, Mazziotti G, Giustina A, and Bilezikian JP. 2007. Glucocorticoid-induced osteoporosis: pathophysiology and therapy. Osteoporos Int 18:1319-1328. 10.1007/s00198-007-03940

Chen SJ, Liao WC, Huang KH, Lin CL, Tsai WC, Kung PT, Chang KH, and Kao CH. 2015. Chronic obstructive pulmonary disease and allied conditions is a strong independent risk factor for osteoporosis and pathologic fractures: a population-based cohort study. Qjm 108:633-640. 10.1093/qjmed/hcv012

Choi YJ, Oh HJ, Kim DJ, Lee Y, and Chung YS. 2012. The prevalence of osteoporosis in Korean adults aged 50 years or older and the higher diagnosis rates in women who were beneficiaries of a national screening program: the Korea National Health and Nutrition Examination Survey 2008-2009. J Bone Miner Res 27:1879-1886. 10.1002/jbmr.1635

Crisan AF, Oancea C, Timar B, Fira-Mladinescu O, and Tudorache V. 2015. Balance impairment in patients with COPD. PLoS One 10:e0120573. 10.1371/journal.pone.0120573

Dam TT, Harrison S, Fink HA, Ramsdell J, and Barrett-Connor E. 2010. Bone mineral density and fractures in older men with chronic obstructive pulmonary disease or asthma. Osteoporos Int 21:1341-1349. 10.1007/s00198-009-1076-x

Dargent-Molina P, Favier F, Grandjean H, Baudoin C, Schott AM, Hausherr E, Meunier PJ, and Breart G. 1996. Fall-related factors and risk of hip fracture: the EPIDOS prospective study. Lancet 348:145-149.

Eisler J, Cornwall R, Strauss E, Koval K, Siu A, and Gilbert M. 2002. Outcomes of elderly patients with nondisplaced femoral neck fractures. Clin Orthop Relat Res:52-58.

Fife D, and Barancik JI. 1985. Northeastern Ohio Trauma Study III: incidence of fractures. Ann Emerg Med 14:244-248.

Graat-Verboom L, Smeenk FW, van den Borne BE, Spruit MA, Jansen FH, van Enschot JW, and Wouters EF. 2012. Progression of osteoporosis in patients with COPD: a 3-year follow up study. Respir Med 106:861-870. 10.1016/j.rmed.2011.12.020

Graat-Verboom L, Wouters EF, Smeenk FW, van den Borne BE, Lunde R, and Spruit MA. 2009. Current status of research on osteoporosis in COPD: a systematic review. Eur Respir J 34:209-218. 10.1183/09031936.50130408 
436

437

438

439

440

441

442

443

444

445

446

447

448

449

450

451

452

453

454

455

456

457

458

459

460

461

462

463

464

465

466

467

468

469

470

471

472

473

474

475

476

477

478

479

Harrison SL, Beauchamp MK, Sibley K, Araujo T, Romano J, Goldstein RS, and Brooks D. 2015. Minimizing the evidence-practice gap - a prospective cohort study incorporating balance training into pulmonary rehabilitation for individuals with chronic obstructive pulmonary disease. BMC Pulm Med 15:73. 10.1186/s12890-015-0067-2

Huang SW, Wang WT, Chou LC, Chen HC, Liou TH, and Lin HW. 2016. Chronic Obstructive Pulmonary Disease Increases the Risk of Hip Fracture: A Nationwide Population-Based Cohort Study. Sci Rep 6:23360. 10.1038/srep23360

Iki M, Kagamimori S, Kagawa Y, Matsuzaki T, Yoneshima H, and Marumo F. 2001. Bone mineral density of the spine, hip and distal forearm in representative samples of the Japanese female population: Japanese Population-Based Osteoporosis (JPOS) Study. Osteoporos Int 12:529-537. 10.1007/s001980170073

Jaramillo JD, Wilson C, Stinson DS, Lynch DA, Bowler RP, Lutz S, Bon JM, Arnold B, McDonald ML, Washko GR, Wan ES, DeMeo DL, Foreman MG, Soler X, Lindsay SE, Lane NE, Genant HK, Silverman EK, Hokanson JE, Make BJ, Crapo JD, and Regan EA. 2015. Reduced Bone Density and Vertebral Fractures in Smokers. Men and COPD Patients at Increased Risk. Ann Am Thorac Soc 12:648-656. 10.1513/AnnalsATS.201412-5910C

Johnell O, and Kanis JA. 2006. An estimate of the worldwide prevalence and disability associated with osteoporotic fractures. Osteoporos Int 17:1726-1733. 10.1007/s00198006-0172-4

Jorgensen NR, and Schwarz P. 2008. Osteoporosis in chronic obstructive pulmonary disease patients. Curr Opin Pulm Med 14:122-127. 10.1097/MCP.0b013e3282f4efb6

Kim HC, Mofarrahi M, and Hussain SN. 2008. Skeletal muscle dysfunction in patients with chronic obstructive pulmonary disease. Int J Chron Obstruct Pulmon Dis 3:637-658.

Klawansky S, Komaroff E, Cavanaugh PF, Jr., Mitchell DY, Gordon MJ, Connelly JE, and Ross SD. 2003. Relationship between age, renal function and bone mineral density in the US population. Osteoporos Int 14:570-576. 10.1007/s00198-003-1435-y

Kok VC, Horng JT, Chang WS, Hong YF, and Chang TH. 2014. Allopurinol therapy in gout patients does not associate with beneficial cardiovascular outcomes: a population-based matched-cohort study. PLoS One 9:e99102. 10.1371/journal.pone.0099102

Kok VC, Horng JT, Hung GD, Xu JL, Hung TW, Chen YC, and Chen CL. 2016. Risk of Autoimmune Disease in Adults with Chronic Insomnia Requiring Sleep-Inducing Pills: A PopulationBased Longitudinal Study. J Gen Intern Med. 10.1007/s11606-016-3717-z

Kok VC, Sung FC, Kao CH, Lin CC, and Tseng CH. 2015a. Cancer risk in East Asian patients associated with acquired haemolytic anaemia: a nationwide population-based cohort study. BMC Cancer 16:57. 10.1186/s12885-016-2098-3

Kok VC, Tsai HJ, Su CF, and Lee CK. 2015b. The Risks for Ovarian, Endometrial, Breast, Colorectal, and Other Cancers in Women With Newly Diagnosed Endometriosis or Adenomyosis: A Population-Based Study. Int J Gynecol Cancer 25:968-976. 10.1097/IGC.0000000000000454

Kulak CA, Borba VC, Jorgetti V, Dos Reis LM, Liu XS, Kimmel DB, Kulak J, Jr., Rabelo LM, Zhou H, Guo XE, Bilezikian JP, Boguszewski CL, and Dempster DW. 2010. Skeletal microstructural abnormalities in postmenopausal women with chronic obstructive pulmonary disease. $J$ Bone Miner Res 25:1931-1940. 10.1002/jbmr.88

Lekamwasam S, Trivedi DP, and Khaw KT. 2002. An association between respiratory function 
480

481

482

483

484

485

486

487

488

489

490

491

492

493

494

495

496

497

498

499

500

501

502

503

504

505

506

507

508

509

510

511

512

513

514

515

516

517

518

519

520

521

522

523

and bone mineral density in women from the general community: a cross sectional study. Osteoporos Int 13:710-715. 10.1007/s001980200097

Lekamwasam S, Trivedi DP, and Khaw KT. 2005. An association between respiratory function and hip bone mineral density in older men: a cross-sectional study. Osteoporos Int 16:204-207. 10.1007/s00198-004-1673-7

Looker AC. 2014. Relationship between femur neck bone mineral density and prevalent chronic obstructive pulmonary disease (COPD) or COPD mortality in older non-Hispanic white adults from NHANES III. Osteoporos Int 25:1043-1052. 10.1007/s00198-013-2601-5

Morden NE, Sullivan SD, Bartle B, and Lee TA. 2011. Skeletal health in men with chronic lung disease: rates of testing, treatment, and fractures. Osteoporos Int 22:1855-1862. 10.1007/s00198-010-1423-y

Nelson HD, Haney EM, Dana T, Bougatsos C, and Chou R. 2010. Screening for osteoporosis: an update for the U.S. Preventive Services Task Force. Ann Intern Med 153:99-111. 10.7326/0003-4819-153-2-201007200-00262

Nickolas TL, Leonard MB, and Shane E. 2008. Chronic kidney disease and bone fracture: a growing concern. Kidney Int 74:721-731. 10.1038/ki.2008.264

Ogura-Tomomatsu H, Asano K, Tomomatsu K, Miyata J, Ohmori N, Kodama M, Ueda S, Takihara T, Tanaka K, Kamiishi N, Suzuki Y, Fukunaga K, Oguma T, Sayama K, and Betsuyaku T. 2012. Predictors of osteoporosis and vertebral fractures in patients presenting with moderate-to-severe chronic obstructive lung disease. Copd 9:332-337. 10.3109/15412555.2012.667850

Poole KE, and Compston JE. 2006. Osteoporosis and its management. BMJ 333:1251-1256. $333 / 7581 / 1251$ [pii]

10.1136/bmj.39050.597350.47

Porto EF, Castro AA, Schmidt VG, Rabelo HM, Kumpel C, Nascimento OA, and Jardim JR. 2015. Postural control in chronic obstructive pulmonary disease: a systematic review. Int J Chron Obstruct Pulmon Dis 10:1233-1239. 10.2147/COPD.S63955

Reid IR, and Heap SW. 1990. Determinants of vertebral mineral density in patients receiving long-term glucocorticoid therapy. Arch Intern Med 150:2545-2548.

Reyes C, Estrada P, Nogues X, Orozco P, Cooper C, Diez-Perez A, Formiga F, Gonzalez-Macias J, and Prieto-Alhambra D. 2014. The impact of common co-morbidities (as measured using the Charlson index) on hip fracture risk in elderly men: a population-based cohort study. Osteoporos Int 25:1751-1758. 10.1007/s00198-014-2682-9

Ries AL, Bauldoff GS, Carlin BW, Casaburi R, Emery CF, Mahler DA, Make B, Rochester CL, Zuwallack R, and Herrerias C. 2007. Pulmonary Rehabilitation: Joint ACCP/AACVPR Evidence-Based Clinical Practice Guidelines. Chest 131:4S-42S. 10.1378/chest.06-2418

Roig M, Eng JJ, Maclntyre DL, Road JD, FitzGerald JM, Burns J, and Reid WD. 2011. Falls in people with chronic obstructive pulmonary disease: an observational cohort study. Respir Med 105:461-469. 10.1016/j.rmed.2010.08.015

Schnell K, Weiss CO, Lee T, Krishnan JA, Leff B, Wolff JL, and Boyd C. 2012. The prevalence of clinically-relevant comorbid conditions in patients with physician-diagnosed COPD: a cross-sectional study using data from NHANES 1999-2008. BMC Pulm Med 12:26. 10.1186/1471-2466-12-26

Schuit SC, van der Klift M, Weel AE, de Laet CE, Burger H, Seeman E, Hofman A, Uitterlinden AG, 
524

525

526

527

528

529

530

531

532

533

534

535

536

537

538

539

540

541

542 van Leeuwen JP, and Pols HA. 2004. Fracture incidence and association with bone mineral density in elderly men and women: the Rotterdam Study. Bone 34:195-202.

Sibley KM, Voth J, Munce SE, Straus SE, and Jaglal SB. 2014. Chronic disease and falls in community-dwelling Canadians over 65 years old: a population-based study exploring associations with number and pattern of chronic conditions. BMC Geriatr 14:22. 10.1186/1471-2318-14-22

Vrieze A, de Greef MH, Wijkstra PJ, and Wempe JB. 2007. Low bone mineral density in COPD patients related to worse lung function, low weight and decreased fat-free mass. Osteoporos Int 18:1197-1202. 10.1007/s00198-007-0355-7

Watanabe R, Tanaka T, Aita K, Hagiya M, Homma T, Yokosuka K, Yamakawa H, Yarita T, Tai N, Hirano J, Inoue D, and Okazaki R. 2015. Osteoporosis is highly prevalent in Japanese males with chronic obstructive pulmonary disease and is associated with deteriorated pulmonary function. J Bone Miner Metab 33:392-400. 10.1007/s00774-014-0605-7

Wu XP, Liao EY, Zhang H, Dai RC, Shan PF, Cao XZ, Liu SP, and Jiang Y. 2004. Determination of age-specific bone mineral density and comparison of diagnosis and prevalence of primary osteoporosis in Chinese women based on both Chinese and World Health Organization criteria. J Bone Miner Metab 22:382-391. 10.1007/s00774-004-0499-x 


\section{Figure legends}

544

545 Figure 1. Consort diagram of the present study flow.

546

547 Figure 2. Cumulative incidence curves of osteoporotic fracture in COPD patients and non-COPD 548 comparators matched for age, sex, index date, pre-existing osteoporosis, diabetes mellitus and 549 chronic kidney disease.

550

551 Figure 3. Cumulative incidence curves of osteoporotic vertebral fracture in COPD patients and 552 non-COPD comparators after multivariate adjustment.

553

554 Supplement Figure 1. Kaplan-Meier fracture-free survival curves of COPD patients and non555 COPD comparators matched for age, sex, index date, pre-existing osteoporosis, diabetes mellitus 556 and chronic kidney disease. 


\section{Figure 1}

Consort diagram of the present study flow.

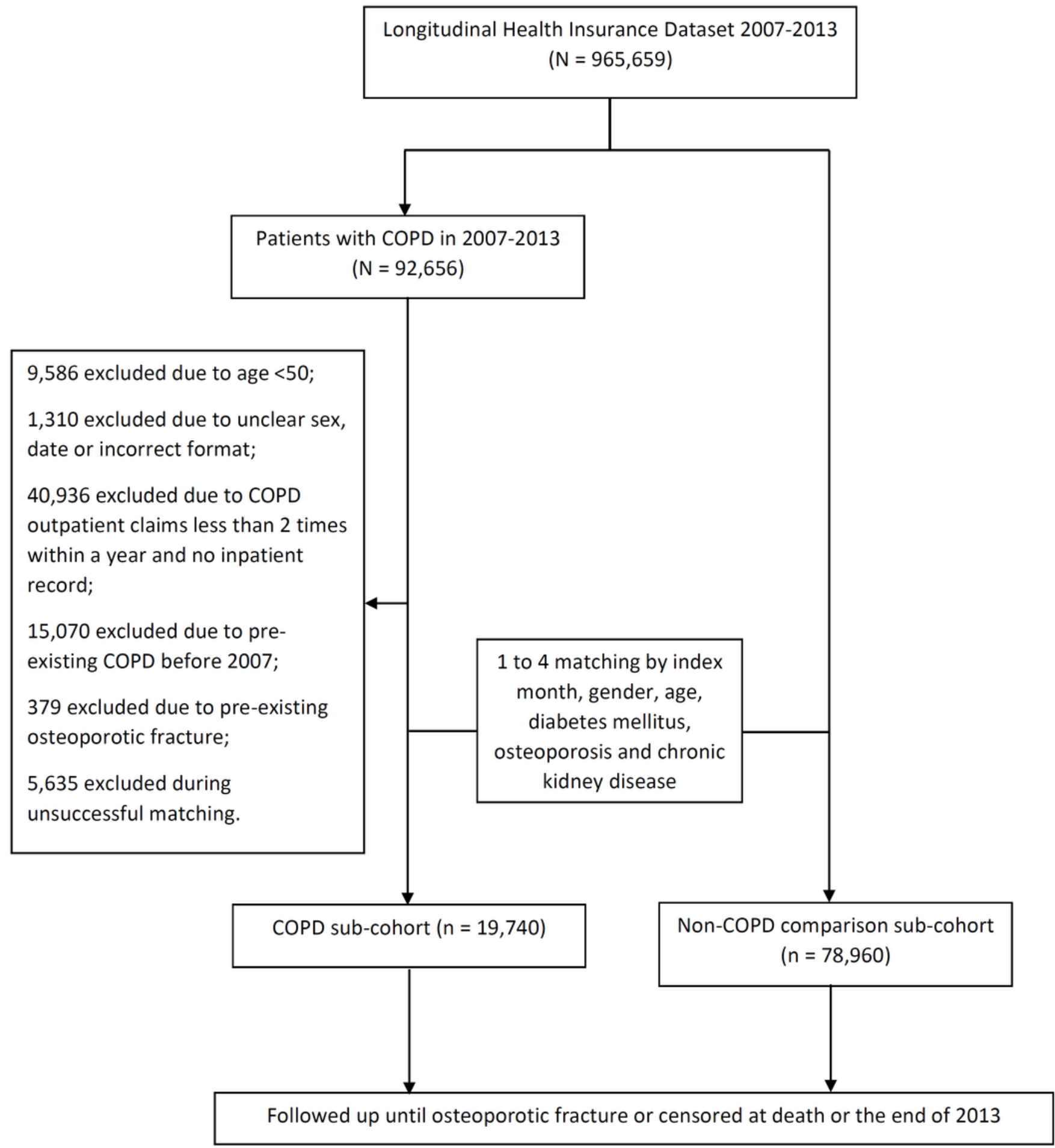


Figure 2

Cumulative incidence curves of osteoporotic fracture in COPD patients and non-COPD comparators matched for age, sex, index date, osteoporosis, diabetes mellitus and chronic kidney disease.

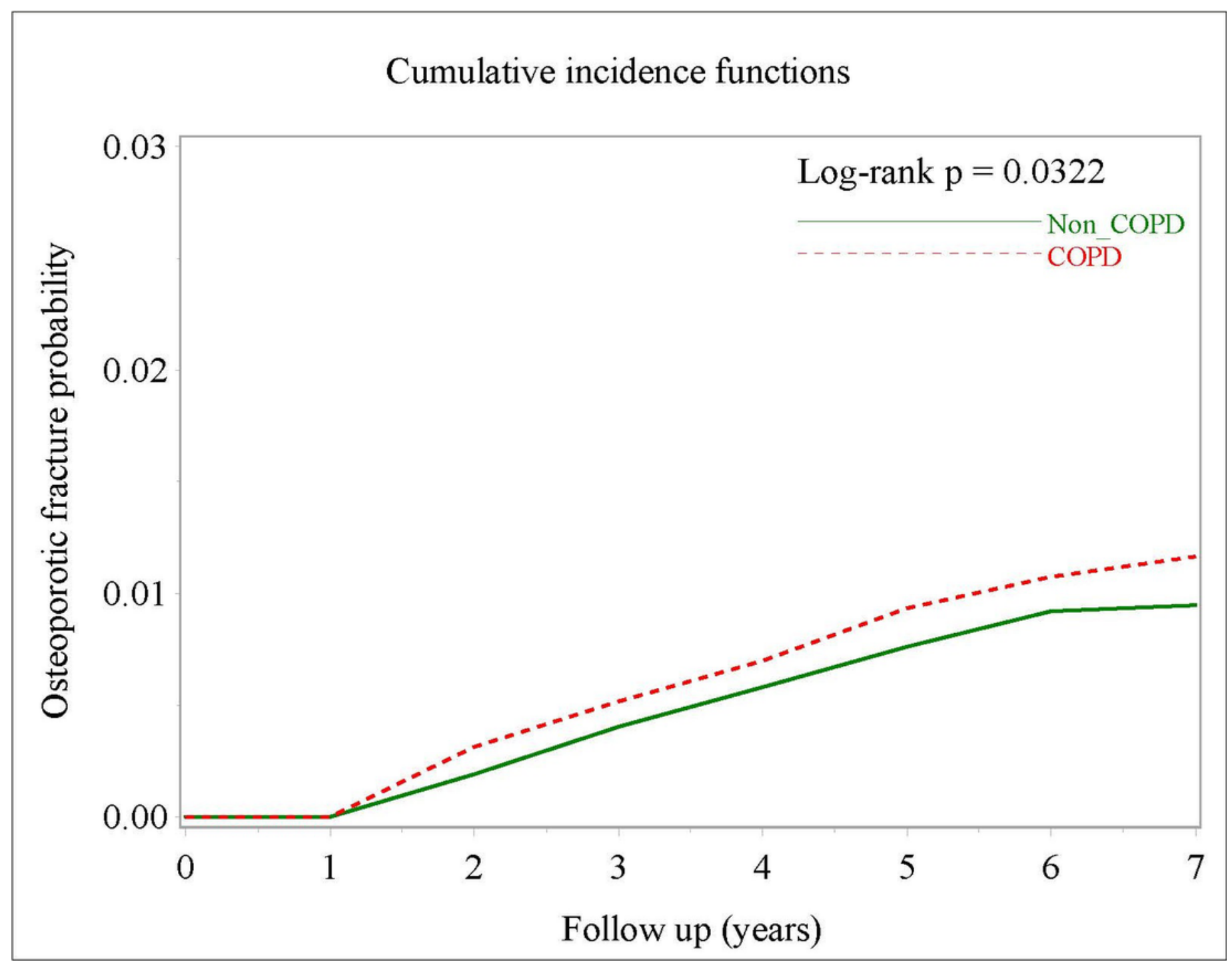


Figure 3

Cumulative incidence curves of osteoporotic vertebral fracture in COPD patients and non-COPD comparators after multivariate adjustment.

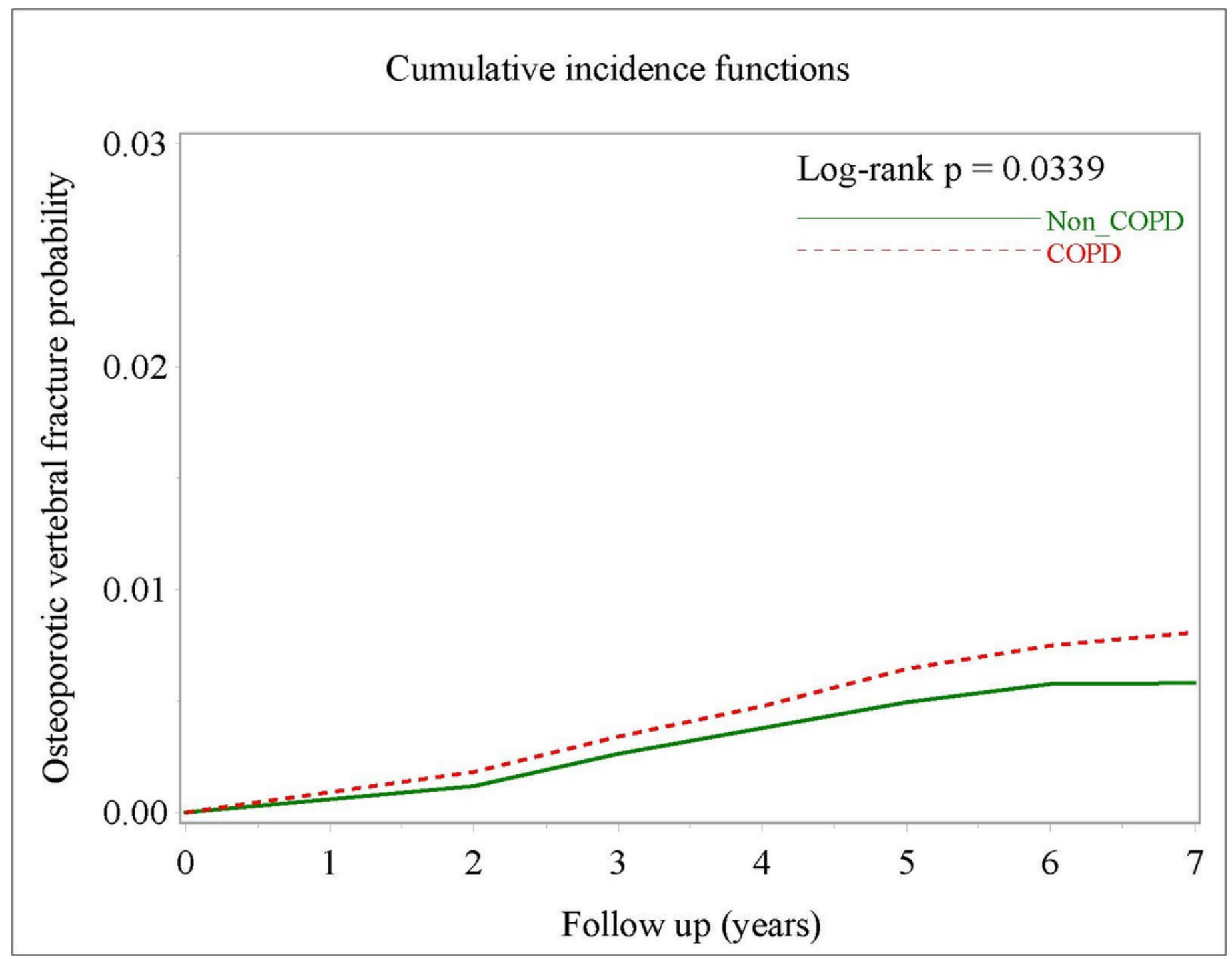




\section{Table $\mathbf{1}$ (on next page)}

Demographic characteristics of COPD patients and Non-COPD patients 1-to-4-matched by age, sex, index date, diabetes mellitus, pre-existing osteoporosis, and chronic kidney disease. 
1 Table 1. Demographic characteristics of COPD patients and Non-COPD patients 1-to-4-matched

2 by age, sex, index date, diabetes mellitus, pre-existing osteoporosis, and chronic kidney disease.

\begin{tabular}{|c|c|c|c|c|c|}
\hline \multirow[t]{2}{*}{ Descriptor } & \multicolumn{2}{|l|}{ COPD patients } & \multicolumn{2}{|l|}{ Non-COPD patients } & \multirow{2}{*}{$P$ value } \\
\hline & $N=19,740$ & (\%) & $N=78,960$ & (\%) & \\
\hline Age mean (SD) & $66.02(10.23)$ & & $65.92(10.23)$ & & 1 \\
\hline \multicolumn{6}{|l|}{ Age group } \\
\hline $50 \sim 59$ & 6423 & 32.54 & 26140 & 33.11 & \\
\hline $60 \sim 69$ & 5915 & 29.96 & 23501 & 29.76 & \\
\hline $70 \sim 79$ & 5077 & 25.72 & 20215 & 25.60 & \\
\hline$>80$ & 2325 & 11.78 & 9104 & 11.53 & \\
\hline Gender & & & & & 1 \\
\hline Female & 8732 & 44.24 & 34928 & 44.24 & \\
\hline Male & 11008 & 55.76 & 44032 & 55.76 & \\
\hline \multicolumn{6}{|l|}{ Other matched characteristics } \\
\hline Diabetes mellitus & 4726 & 23.94 & 18904 & 23.94 & 1 \\
\hline Osteoporosis & 1187 & 6.01 & 4748 & 6.01 & 1 \\
\hline Chronic kidney disease & 2746 & 13.91 & 10984 & 13.91 & 1 \\
\hline Follow-up (Year) / Mean (SD) & $2.97(2.06)$ & & $3.01(2.05)$ & & 0.0949 \\
\hline 1 & 3051 & 15.46 & 11618 & 14.71 & \\
\hline 2 & 2976 & 15.08 & 11707 & 14.83 & \\
\hline 3 & 2820 & 14.29 & 11355 & 14.38 & \\
\hline 4 & 2575 & 13.04 & 10442 & 13.22 & \\
\hline 5 & 2523 & 12.78 & 10309 & 13.06 & \\
\hline 6 & 2597 & 13.16 & 10754 & 13.62 & \\
\hline 7 & 3170 & 16.06 & 12691 & 16.07 & \\
\hline Residential Area & & & & & $<0.0001$ \\
\hline North & 8386 & 42.48 & 34410 & 43.58 & \\
\hline Central & 5300 & 26.85 & 19132 & 24.23 & \\
\hline South & 5330 & 27.00 & 22655 & 28.69 & \\
\hline East & 591 & 2.99 & 1934 & 2.45 & \\
\hline Smoking-related Diagnoses & 12353 & 62.58 & 2772 & 3.51 & $<0.0001$ \\
\hline Alcohol use disorder & 598 & 3.03 & 1557 & 1.97 & $<0.0001$ \\
\hline Insurance Premium Category & & & & & $<0.0001$ \\
\hline
\end{tabular}




\begin{tabular}{|c|c|c|c|c|c|}
\hline$<15,000$ NTD & 10041 & 50.87 & 39186 & 49.63 & \\
\hline $15,000-21,999$ NTD & 6028 & 30.54 & 23634 & 29.93 & \\
\hline$\geq 22,000$ NTD & 3671 & 18.60 & 16140 & 20.44 & \\
\hline \multicolumn{6}{|l|}{ Comorbidities } \\
\hline Rheumatoid Arthritis & 545 & 2.76 & 1790 & 2.27 & $<0.0001$ \\
\hline Hypertension & 11509 & 58.30 & 44266 & 56.06 & $<0.0001$ \\
\hline Dyslipidemia & 6813 & 34.51 & 27511 & 34.84 & 0.3868 \\
\hline Coronary heart disease & 5528 & 28.00 & 17192 & 21.77 & $<0.0001$ \\
\hline Liver disease & 3824 & 19.37 & 13644 & 19.28 & $<0.0001$ \\
\hline Stroke & 3994 & 20.23 & 12188 & 15.44 & $<0.0001$ \\
\hline Dementia & 1144 & 5.80 & 2481 & 3.14 & $<0.0001$ \\
\hline \multicolumn{6}{|l|}{ Type of ICS } \\
\hline Budesonide & 1214 & 6.17 & 440 & 0.56 & $<0.0001$ \\
\hline Beclomethasone & 267 & 1.36 & 169 & 0.21 & $<0.0001$ \\
\hline Ciclesonide & 46 & 0.23 & 16 & 0.02 & $<0.0001$ \\
\hline Fluticasone & 1762 & 8.96 & 425 & 0.54 & $<0.0001$ \\
\hline \multicolumn{6}{|l|}{ Type of OCS } \\
\hline Cortisone acetate & 62 & 0.32 & 125 & 0.16 & $<0.0001$ \\
\hline Dexamethasone & 325 & 1.65 & 770 & 0.98 & $<0.0001$ \\
\hline Fludrocortisone & 18 & 0.09 & 51 & 0.06 & $<0.0001$ \\
\hline Methylprednisolone & 373 & 1.90 & 656 & 0.83 & $<0.0001$ \\
\hline Prednisolone & 3330 & 16.93 & 5012 & 6.36 & $<0.0001$ \\
\hline Triamcinolone & 30 & 0.15 & 97 & 0.12 & $<0.0001$ \\
\hline Vitamin D prescription & 487 & 2.48 & 1689 & 2.14 & 0.0045 \\
\hline CCl score / Mean (SD) & $1.14(1.36)$ & & $1.02(1.32)$ & & $<0.0001$ \\
\hline $\mathrm{CCl}$ score 0 & 8604 & 43.59 & 38699 & 49.01 & \\
\hline $\mathrm{CCl}$ score 1,2 & 8051 & 40.79 & 29345 & 37.16 & \\
\hline $\mathrm{CCl}$ score 3,4 & 2308 & 11.69 & 8235 & 10.43 & \\
\hline $\mathrm{CCl}$ score $\geq 5$ & 777 & 3.94 & 2681 & 3.40 & \\
\hline
\end{tabular}

3

$4{ }^{*}$ COPD was excluded from the $\mathrm{CCl}$ score in the COPD cohort.

5 CCI: Charlson-Deyo comorbidity index; ICS: inhaled corticosteroid; NTD: New Taiwan Dollar; OCS: oral

6 corticosteroid; SD: standard deviation 


\section{Table 2 (on next page)}

Table_2_revised_no_track.docx

Incidence of osteoporotic fractures for COPD patients compared with non-COPD patients and crude and adjusted hazard ratio for an episode of osteoporotic fracture 
Table 2. Incidence of osteoporotic fractures for COPD patients compared with non-COPD patients and crude and adjusted hazard ratio for an episode of osteoporotic fracture

\begin{tabular}{|c|c|c|c|c|c|c|c|c|c|}
\hline \multirow[t]{2}{*}{ Variables } & \multicolumn{3}{|c|}{ COPD patients } & \multicolumn{3}{|c|}{ Non-COPD patients } & \multirow{2}{*}{$\begin{array}{l}\text { Incidence Rate Ratio } \\
\qquad(95 \% \mathrm{Cl})\end{array}$} & \multirow{2}{*}{ Crude HR } & \multirow{2}{*}{ Adjusted HR* } \\
\hline & Event & PY & Rate & Event & PY & Rate & & & \\
\hline All & 131 & 68743.3 & 1.91 & 429 & 278050.7 & 1.54 & $1.24(1.01-1.51)$ & $\begin{array}{c}1.24(1.02-1.51) \\
(P=0.0322)\end{array}$ & $\begin{array}{c}1.207(0.992-1.469 \\
(P=0.0597) \\
\end{array}$ \\
\hline Vertebral fractures & 89 & 68743.3 & 1.29 & 271 & 278050.7 & 0.97 & 1.33 (1.03-1.69) & $\begin{array}{c}1.33(1.05-1.69) \\
(P=0.0189)\end{array}$ & $\begin{array}{c}1.297(1.020-1.649) \\
(P=0.0339)\end{array}$ \\
\hline Ulna fractures & 1 & 68743.3 & 0.01 & 3 & 278050.7 & 0.01 & 1.35 (0.03-16.79) & $\begin{array}{c}1.35(0.14-12.99) \\
\quad(P=0.7943)\end{array}$ & \\
\hline $\begin{array}{l}\text { Neck of femur } \\
\text { fractures }\end{array}$ & 4 & 68743.3 & 0.06 & 7 & 278050.7 & 0.03 & $2.31(0.50-9.09)$ & $\begin{array}{c}2.319(0.68-7.92) \\
\quad(P=0.1797)\end{array}$ & \\
\hline \multicolumn{10}{|l|}{ Age } \\
\hline $50-59$ & 10 & 23495.89 & 0.43 & 22 & 96405.22 & 0.23 & $1.87(0.79-4.10)$ & 1 & 1 \\
\hline $70-79$ & 62 & 17398.42 & 3.56 & 188 & 69866.2 & 2.69 & $1.32(0.98-1.77)$ & $\begin{array}{c}8.44(4.33-16.46) \\
(P<0.0001)\end{array}$ & $\begin{array}{c}7.124(3.395- \\
14.951) \\
(P<0.0001)\end{array}$ \\
\hline$>80$ & 30 & 7051.96 & 4.25 & 125 & 28579.67 & 4.37 & $0.97(0.63-1.46)$ & $\begin{array}{c}10.33(5.05-21.13) \\
(P<0.0001)\end{array}$ & $\begin{array}{c}7.482(3.299- \\
16.971) \\
(P<0.0001) \\
\end{array}$ \\
\hline \multicolumn{10}{|l|}{ Sex } \\
\hline Male & 23 & 37817.02 & 0.61 & 57 & 152742 & 0.37 & $1.63(0.96-2.69)$ & 1 & 1 \\
\hline Female & 108 & 30926.28 & 3.49 & 372 & 125308.8 & 2.97 & $1.18(0.94-1.46)$ & $\begin{array}{c}5.70(3.64-8.95) \\
(P<0.0001)\end{array}$ & $\begin{array}{c}3.817(2.388-6.1) \\
(P<0.0001)\end{array}$ \\
\hline
\end{tabular}




\begin{tabular}{|c|c|c|c|c|c|c|c|c|c|}
\hline Vitamin D prescripti & & & & & & & & & \\
\hline No & 108 & 66601.18 & 1.62 & 380 & 270804.9 & 1.4 & $1.16(0.92-1.43)$ & 1 & 1 \\
\hline Yes & 23 & 2142.12 & 10.74 & 49 & 7245.82 & 6.76 & $1.59(0.92-2.66)$ & $\begin{array}{c}6.375(4.06-10.00) \\
(P<0.0001)\end{array}$ & $\begin{array}{c}3.3(2.08-5.236) \\
(P<0.0001)\end{array}$ \\
\hline \multicolumn{10}{|l|}{ Steroid exposuret } \\
\hline No steroid & 92 & 41622.03 & 2.21 & 364 & 219780.6 & 1.66 & $1.33(1.05-1.68)$ & 1 & \\
\hline ICS regular use & 1 & 2768.1 & 0.36 & 1 & 688.57 & 1.45 & $0.25(0.003-19.53)$ & $\begin{array}{c}0.154(0.022-1.107) \\
(P=0.0631)\end{array}$ & \\
\hline OCS regular use & 1 & 1097.32 & 0.91 & 1 & 2294.96 & 0.44 & $2.09(0.03-164.17)$ & $\begin{array}{c}0.391(0.055-2.807) \\
(P=0.3506)\end{array}$ & \\
\hline No & 56 & 26518.7 & 2.11 & 419 & 269633.1 & 1.55 & $1.36(1.01-1.80)$ & 1 & \\
\hline Yes & 75 & 42224.6 & 1.78 & 10 & 8417.64 & 1.19 & $1.50(0.77-3.24)$ & $\begin{array}{c}0.848(0.6-1.20) \\
\quad(P=0.3497)\end{array}$ & \\
\hline \multicolumn{10}{|l|}{ Alcohol use disorders } \\
\hline No & 131 & 67001.73 & 1.96 & 429 & 273623.2 & 1.57 & $1.25(1.02-1.52)$ & 1 & \\
\hline Yes & 0 & 1741.57 & NA & 0 & 4427.45 & NA & NA & NA & \\
\hline \multicolumn{10}{|l|}{$\begin{array}{l}\text { Insurance premium } \\
\text { (NTD) }\end{array}$} \\
\hline$<15,000$ & 64 & 34007.32 & 1.88 & 257 & 135747.5 & 0.99 & $0.99(0.74-1.31)$ & 1 & 1 \\
\hline
\end{tabular}




\begin{tabular}{|c|c|c|c|c|c|c|c|c|c|}
\hline $15,000-21,999$ & 60 & 21653.09 & 2.77 & 158 & 84330.74 & 1.87 & $1.48(1.08-2.00)$ & $\begin{array}{c}3.56(1.63-7.76) \\
\quad(P=0.0014)\end{array}$ & $\begin{array}{c}1.394(0.583-3.335) \\
(P=0.4554)\end{array}$ \\
\hline$\geq 22,000$ & 7 & 13082.89 & 0.54 & 14 & 57972.41 & 0.24 & $2.22(0.76-5.87)$ & $\begin{array}{c}5.18(2.37-11.33) \\
(P<0.0001)\end{array}$ & $\begin{array}{c}1.171(0.472-2.901) \\
(P=0.7338)\end{array}$ \\
\hline \multicolumn{10}{|l|}{ Geographic area } \\
\hline North & 54 & 29259.38 & 1.85 & 175 & 121378.3 & 1.44 & $1.28(0.93-1.75)$ & 1 & \\
\hline Central & 45 & 18457 & 2.44 & 141 & 66933.68 & 2.11 & $1.16(0.81-1.63)$ & $\begin{array}{c}1.32(0.89-1.97) \\
(P=0.1658)\end{array}$ & \\
\hline South & 29 & 18390.64 & 1.58 & 101 & 79909.28 & 1.26 & $1.25(0.80-1.91)$ & $\begin{array}{c}0.856(0.55-1.35) \\
(P=0.50)\end{array}$ & \\
\hline East & 3 & 2130.77 & 1.41 & 7 & 6843.38 & 1.02 & $1.38(0.23-6.03)$ & $\begin{array}{c}0.76(0.23-2.43) \\
\quad(P=0.6414)\end{array}$ & \\
\hline \multicolumn{10}{|l|}{ Comorbidities } \\
\hline \multicolumn{10}{|c|}{ Rheumatoid Arthritis } \\
\hline No & 129 & 67096.49 & 1.92 & 407 & 272383.3 & 1.49 & $1.29(1.05-1.57)$ & 1 & \\
\hline Yes & 2 & 1646.81 & 1.21 & 22 & 5667.4 & 3.88 & $0.31(0.04-1.27)$ & $\begin{array}{c}0.651(0.161-2.629) \\
(P=0.5463)\end{array}$ & \\
\hline \multicolumn{10}{|l|}{ Diabetes mellitus } \\
\hline No & 102 & 53458.33 & 1.91 & 349 & 216876.3 & 1.61 & $1.19(0.94-1.48)$ & 1 & \\
\hline Yes & 29 & 15284.97 & 1.9 & 80 & 61174.37 & 1.31 & $1.45(0.91-2.24)$ & $\begin{array}{c}1.015(0.672-1.533) \\
(P=0.9449)\end{array}$ & \\
\hline \multicolumn{10}{|l|}{ Hypertension } \\
\hline No & 52 & 29753.16 & 1.75 & 149 & 128167.5 & 1.16 & $1.50(1.07-2.07)$ & 1 & \\
\hline
\end{tabular}




\begin{tabular}{|c|c|c|c|c|c|c|c|c|c|}
\hline Yes & 79 & 38990.13 & 2.03 & 280 & 149883.2 & 1.87 & $1.08(0.83-1.40)$ & $\begin{array}{c}1.176(0.829-1.669) \\
(P=0.3646)\end{array}$ & \\
\hline \multicolumn{10}{|l|}{ Dyslipidemia } \\
\hline No & 81 & 46397.68 & 1.75 & 287 & 188947.6 & 1.52 & $1.15(0.89-1.48)$ & 1 & \\
\hline Yes & 50 & 22345.62 & 2.24 & 142 & 89103.05 & 1.59 & $1.40(1.00-1.95)$ & $\begin{array}{c}1.305(0.917-1.858) \\
(P=0.1386)\end{array}$ & \\
\hline \multicolumn{10}{|c|}{ Osteoporosis } \\
\hline No & 93 & 65071.05 & 1.43 & 297 & 262971.8 & 1.13 & $1.27(0.99-1.60)$ & 1 & 1 \\
\hline Yes & 38 & 3672.25 & 10.35 & 132 & 15078.89 & 8.75 & $1.18(0.80-1.71)$ & $\begin{array}{c}7.399(5.071-10.796) \\
(P<0.0001)\end{array}$ & $\begin{array}{c}3.01(2.019-4.487) \\
(P<0.0001)\end{array}$ \\
\hline \multicolumn{10}{|c|}{$\begin{array}{l}\text { Coronary heart } \\
\text { disease }\end{array}$} \\
\hline No & 75 & 50255.5 & 1.49 & 299 & 222287.6 & 1.35 & $1.11(0.85-1.43)$ & 1 & 1 \\
\hline Yes & 56 & 18487.79 & 3.03 & 130 & 55763.07 & 2.33 & $1.30(0.93-1.79)$ & $\begin{array}{c}2.05(1.45-2.899) \\
(P<0.0001)\end{array}$ & $\begin{array}{c}1.471(1.037-2.088) \\
(P=0.0306)\end{array}$ \\
\hline \multicolumn{10}{|c|}{$\begin{array}{l}\text { Chronic kidney } \\
\text { disease }\end{array}$} \\
\hline No & 113 & 60552.14 & 2.24 & 375 & 245400 & 1.83 & $1.22(0.98-1.51)$ & 1 & \\
\hline Yes & 18 & 8191.16 & 2.2 & 54 & 32650.65 & 1.65 & $1.33(0.73-2.30)$ & $\begin{array}{c}1.222(0.743-2.010) \\
(P=0.4303)\end{array}$ & \\
\hline \multicolumn{10}{|l|}{ Liver disease } \\
\hline No & 109 & 56439.49 & 1.93 & 352 & 235095.9 & 1.5 & $1.29(1.03-1.60)$ & 1 & \\
\hline
\end{tabular}




\begin{tabular}{c|r|r|r|r|r|r|r|r|l}
\hline \multicolumn{1}{c|}{ Yes } & 22 & 12303.81 & 1.79 & 77 & 42954.81 & 1.79 & $1.0(0.59-1.62)$ & $\begin{array}{c}0.944(0.597-1.493) \\
(P=0.8051)\end{array}$ & \\
\hline \multicolumn{1}{l|}{ Stroke } & 111 & 56270.64 & 1.97 & 343 & 238988.5 & 1.44 & $1.37(1.10-1.71)$ & 1 & \\
\hline No & 20 & 12472.65 & 1.6 & 86 & 39062.17 & 2.2 & $0.73(0.42-1.20)$ & $\begin{array}{c}0.834(0.518-1.344) \\
(P=0.456)\end{array}$ & \\
\hline Yes & 125 & 65485.98 & 1.91 & 408 & 270683.4 & 1.51 & $1.26(1.03-1.55)$ & 1 & \\
\hline Nomentia & 6 & 3257.32 & 1.84 & 21 & 7367.3 & 2.85 & $0.65(0.21-1.66)$ & $\begin{array}{c}1.003(0.442-2.277) \\
(P=0.9934)\end{array}$ & \\
\hline Yes & & & & & & & & \\
\hline
\end{tabular}

Hazard ratio calculation: For fracture sites, comparison was made between COPD and nonCOPD; in subcategories such as age and sex, HR is based on the comparison among subcategories with the reference group.

Event $=$ Number of Osteoporotic Fractures; PY $=$ Person Years; Rate = Incidence per 1,000 PY; $C K D=$ Chronic kidney disease; $H R=$ Hazard Ratio; ICS = inhaled corticosteroids; IHD = Ischemic heart disease; NA = not applicable; OCS = oral corticosteroids.

* Multivariate Cox regression model derived HR was adjusted for sex, age group, vitamin D prescription, insurance premium category, pre-existing osteoporosis and coronary heart disease.

tOnly regular users by pre-determined definitions were included for analysis.

Bold type numerals denote statistical significance. 


\section{Table 3(on next page)}

Sensitivity Analysis.

Table 3. Sensitivity analysis showing the effect of differential time lag on the risk of osteoporotic fractures among COPD patients who possessed the characteristic 
2 Table 3. Sensitivity analysis showing the effect of differential time lag on the risk of osteoporotic vertebral fractures among COPD 3 patients who possessed the contributing characteristics.

\begin{tabular}{|c|c|c|c|c|c|c|c|c|c|c|c|c|c|c|c|c|c|}
\hline \multirow[b]{2}{*}{ Predictive Variable } & \multicolumn{3}{|c|}{$2^{\text {nd }}$ follow up year } & \multicolumn{3}{|c|}{$3^{\text {rd }}$ follow up year } & \multicolumn{3}{|c|}{$4^{\text {th }}$ follow up year } & \multicolumn{3}{|c|}{$5^{\text {th }}$ follow up year } & \multicolumn{3}{|c|}{$6^{\text {th }}$ follow up year } & \multicolumn{2}{|c|}{$7^{\text {th }}$ follow up } \\
\hline & $x / y$ & $A / B$ & $\begin{array}{c}\text { aHR }(95 \% \\
\mathrm{Cl})\end{array}$ & $x / y$ & $A / B$ & $\begin{array}{c}\text { aHR }(95 \% \\
\mathrm{Cl})\end{array}$ & $x / y$ & $A / B$ & $\begin{array}{c}\text { aHR }(95 \% \\
\mathrm{Cl})\end{array}$ & $x / y$ & $\mathrm{~A} / \mathrm{B}$ & $\begin{array}{c}\text { aHR }(95 \% \\
\mathrm{Cl})\end{array}$ & $x / y$ & $A / B$ & $\begin{array}{c}\text { aHR }(95 \% \\
\mathrm{Cl})\end{array}$ & $x / y$ & $A / B$ \\
\hline Female & $\begin{array}{l}7439 / \\
9222\end{array}$ & $72 / 17$ & \begin{tabular}{|c|}
$3.3(1.89-$ \\
$5.74)^{* * * *}$
\end{tabular} & $\begin{array}{l}6177 / \\
7508 \\
\end{array}$ & $48 / 11$ & \begin{tabular}{|c|}
$3.48(1.75-$ \\
$6.9)^{* * *}$
\end{tabular} & \begin{tabular}{|c|}
$4909 /$ \\
5956
\end{tabular} & $31 / 6$ & \begin{tabular}{|c|}
$4.46(1.81-$ \\
$11.03)^{* *}$ \\
\end{tabular} & \begin{tabular}{|c|}
$3762 /$ \\
4528 \\
\end{tabular} & $20 / 2$ & \begin{tabular}{|c|}
$8.0(1.81-$ \\
$35.4)^{* *}$ \\
\end{tabular} & \begin{tabular}{|c|}
$2623 /$ \\
3144
\end{tabular} & $8 / 0$ & - & $\begin{array}{l}1444 / \\
1726\end{array}$ & $2 / 0$ \\
\hline Osteoporosis & $\begin{array}{c}959 / \\
15702 \\
\end{array}$ & $27 / 62$ & \begin{tabular}{|l|}
$3.31(2.04-$ \\
$5.35)^{* * * *}$
\end{tabular} & \begin{tabular}{|c|}
$758 /$ \\
12927 \\
\end{tabular} & $17 / 42$ & \begin{tabular}{|l|}
$3.35(1.84-$ \\
$6.09)^{* * * *}$ \\
\end{tabular} & \begin{tabular}{|c|}
$568 /$ \\
10297 \\
\end{tabular} & $10 / 27$ & \begin{tabular}{|c|}
$3.51(1.64-$ \\
$7.51)^{* *}$
\end{tabular} & \begin{tabular}{|l|}
$393 /$ \\
7897 \\
\end{tabular} & $7 / 15$ & \begin{tabular}{|c|}
$4.08(1.61-$ \\
$10.35)^{* *}$
\end{tabular} & \begin{tabular}{|l|}
$253 /$ \\
5514 \\
\end{tabular} & $2 / 6$ & \begin{tabular}{|c|}
$2.45(0.48-$ \\
$12.41)$
\end{tabular} & $\begin{array}{l}125 / \\
3045\end{array}$ & $1 / 1$ \\
\hline $\begin{array}{l}\text { Vitamin D } \\
\text { Prescription }\end{array}$ & $\begin{array}{c}468 / \\
16193\end{array}$ & $17 / 72$ & $\begin{array}{l}3.62(2.1- \\
6.23)^{* * * *}\end{array}$ & $\begin{array}{c}419 / \\
13266\end{array}$ & $10 / 49$ & \begin{tabular}{|c|}
$2.97(1.48-$ \\
$5.97)^{* *}$
\end{tabular} & $\begin{array}{c}360 / \\
10505\end{array}$ & $4 / 33$ & $\begin{array}{c}1.69(0.59- \\
4.87)\end{array}$ & $\begin{array}{l}295 / \\
7995\end{array}$ & $3 / 19$ & $\begin{array}{c}1.9(0.55- \\
6.57)\end{array}$ & $\begin{array}{l}212 / \\
5555\end{array}$ & $2 / 6$ & $\begin{array}{c}4.48(0.88- \\
22.9)\end{array}$ & $\begin{array}{l}116 / \\
3054\end{array}$ & $1 / 1$ \\
\hline $\begin{array}{l}\text { Coronary Heart } \\
\text { Disease }\end{array}$ & $\begin{array}{l}4590 / \\
12071\end{array}$ & $38 / 51$ & $\begin{array}{c}1.45(0.95- \\
2.22)\end{array}$ & \begin{tabular}{|c|}
$3724 /$ \\
9961
\end{tabular} & $24 / 35$ & $\mid \begin{array}{c}1.39(0.82- \\
2.34)\end{array}$ & $\begin{array}{c}2913 / \\
7952\end{array}$ & $12 / 25$ & $\begin{array}{c}1.04(0.52- \\
2.09)\end{array}$ & $\begin{array}{c}2148 / \\
6142\end{array}$ & $7 / 15$ & \begin{tabular}{|c|}
$0.97(0.39-$ \\
$2.41)$
\end{tabular} & $\begin{array}{c}1437 / \\
4330\end{array}$ & $2 / 6$ & $\begin{array}{c}0.69(0.14- \\
3.47)\end{array}$ & $\begin{array}{l}764 / \\
2406\end{array}$ & $0 / 2$ \\
\hline
\end{tabular}

5 Bold type numerals denote achieving statistically significant. ${ }^{*} \mathrm{P}<0.05 ;{ }^{*} \mathrm{P}<0.01 ;{ }^{* * *} \mathrm{P}<0.001 ;{ }^{* * * * \mathrm{P}<0.0001}$

$6 \mathrm{x} / \mathrm{y}$ : number of patients at risk with the characteristic/number of patients at risk without the characteristic.

7 A/B: number of patients who developed osteoporotic fracture in X/number of patients who developed osteoporotic fracture in $Y$.

8 The Cox model was adjusted for sex, age group, vitamin D prescription, and pre-existing osteoporosis. 